\title{
A Model for Precipitation Kinetics and Strengthening in Al-Cu-Mg Alloys
}

\author{
I.N. Khan, M.J. Starink, J.L. Yan \\ Materials Research Group, School of Engineering Sciences, University of Southampton, \\ Southampton, SO17 1BJ, United Kingdom
}

\begin{abstract}
A physically-based numerical model is developed to predict the microstructural evolution and strengthening in Al-Cu-Mg alloys during isothermal treatments. The modelling of the formation kinetics of the precipitates is based on the Kampmann and Wagner model. The strengthening by the shearable $\mathrm{Cu}: \mathrm{Mg}$ co-clusters is modelled on the basis of modulus strengthening mechanism and the strengthening by the non-shearable $\mathrm{S}$ phase precipitates is based on the Orowan looping mechanism. The model predictions are verified by comparing with the strength and differential isothermal calorimetery data on 2024-T351 aluminium alloys. The microstructural development and strength predictions of the model are generally in good agreement with the experimental data.
\end{abstract}

Keywords: Aluminium alloys; Ageing; Modelling; Precipitation kinetics; Co-clusters

\section{Introduction}

There has been considerable interest in the modelling of precipitation kinetics and strengthening in age hardening aluminium alloys $[1,2,3,4,5,6,7,8,9,10,11,12,13]$. Most of the published work on modelling of the precipitation kinetics in aluminium alloys is based on two main approaches [1-10]. In one of the approaches, the modelling of the nucleation, growth and impingement of precipitates are based on the concepts of the Johnson-Mehl-AvramiKolmogorov (JMAK) model $[14,15,16]$ and the modelling of the coarsening kinetics is based on the Lifshitz-Slyozov-Wagner (LSW) theory $[17,18]$. In the other approach the Kampmann and Wagner (KW) type numerical model [19] is used to predict the complete precipitation kinetics from the nucleation to the coarsening stages. The modelling of the precipitation strengthening is based mainly on the interaction of the precipitates (both shearable and nonshearable) with the dislocations [20].

The aim of the present work is to derive a model for the precipitation kinetics and strengthening in an age hardening aluminium alloy, containing a low and a high temperature hardening phase, by employing the KW numerical model and to test the model predictions for a range of isothermal ageing temperatures.

In the present work the model predictions are validated by comparing with experimental data measured on 2024-T351 aluminium alloys. Due to their good combination of strength and fatigue resistance, 2024 aluminium alloys are extensively used as structural materials in 
commercial aircrafts and their strength is significantly increased by precipitation strengthening [21]. In the alloys with $\mathrm{Cu}: \mathrm{Mg}$ atomic ratio close to 1, the structure and chemistry of some of the (pre-)precipitates appearing during ageing is controversial and the precipitation sequence is indicated in most recent works $[22,23,24,25,26]$ by:

$\alpha_{\mathrm{ss}} \rightarrow \mathrm{Cu}: \mathrm{Mg}$ co-clusters / GPB zones $\rightarrow$ GPB2 / $\mathrm{S}^{\prime \prime}$ phase $\rightarrow \mathrm{S}^{\prime} / \mathrm{S}$ phase

where $\alpha_{\mathrm{ss}}$ stands for super-saturated solid solution, GPB stands for Guinier Preston Bagaryatsky [27] zones, $\mathrm{S}$ phase is the $\mathrm{Al}_{2} \mathrm{CuMg}$ equilibrium phase. An intermediate phase is alternately referred to as GPB2 or S" phase [24,28].

The controversial issues are the differentiation between the co-clusters and the GPB zones, the formation of the GPB2/S" phase and the differentiation between the S phase and slightly strained variants thereof which are sometimes termed $\mathrm{S}^{\prime}$ (or even $\mathrm{S}^{\prime \prime}$ ). Although their existence is often cited, the existence of GPB zones has not been confirmed, and recent studies involving three dimensional atomic probe analysis (3DAP) indicate the formation of $\mathrm{Cu}: \mathrm{Mg}$ co-clusters during initial ageing in these alloys [29]. There is evidence of the formation of an intermediate phase, alternately termed GPB2 or S" phase, but for alloys with more than about $1 \mathrm{wt} \% \mathrm{Cu}$, it is mostly considered to have very limited influence on the strengthening [29]. The meta-stable $\mathrm{S}^{\prime}$ and the equilibrium $\mathrm{S}$ phases are generally not considered as distinct phases due to very similar composition and crystal structure [29,30]. Also it should be noted that no clear evidence exist that $\mathrm{S}$ phase forms through transformation of any precursors: it appears to nucleate independently from any precursors (see e.g. [29]). This allows us to apply a simplified precipitation sequence in the present work, which permits formulation of precipitation kinetics and strengthening model with transparent predictions $[8,29]$ :

$\alpha_{\mathrm{ss}} \rightarrow \mathrm{Cu}: \mathrm{Mg}$ co-clusters $\rightarrow \mathrm{S}$ phase precipitates

This precipitation sequence is consistent with the two stage strengthening observed in these alloys with the initial stage attributed to the strengthening by the $\mathrm{Cu}: \mathrm{Mg}$ co-clusters and the later stage attributed to the strengthening by the $\mathrm{S}$ phase precipitates $[8,31,32]$.

\section{The Model}

The model comprises of two integrated components for the prediction of the precipitation kinetics during ageing and the strengthening as consequence of the microstructural evolution.

Precipitation Kinetics Model: The modelling of precipitation kinetics is based on the Kampmann and Wagner (KW) type numerical model [19], which has been used by several researchers [3-6,9-10]. The model is formulated in a pseudo-binary approximation. Expanding the model to three components $(\mathrm{Al}, \mathrm{Cu}, \mathrm{Mg}$ ) or more is possible (following principles outlined in $[33,35]$ ), but at present this is not pursued as it will add little to the basic insights to be obtained from the present alloys with $\mathrm{Cu}: \mathrm{Mg}$ ratio close to unity. 
In the model, the precipitation process of $\mathrm{S}$ phase is evaluated in terms of a number of discreet small time steps during which new precipitates may nucleate and existing precipitates either grow or shrink. The new precipitates forming during each time step are treated as individual groups and their growth (or dissolution) is evaluated in the subsequent time steps as distinct groups.

Co-clusters: In solution treated and quenched Al-Cu-Mg alloys, the co-clusters may form very rapidly (within minutes) at temperatures in the order of $100^{\circ} \mathrm{C}$ or within a few days during ageing at room temperature. As all the treatments applied in the present work involve such ageing conditions, we will assume that all $\mathrm{Cu}$ and $\mathrm{Mg}$ not taken up by other precipitates will form co-clusters up to an amount that is determined by the semi-equilibrium solvus for the coclusters. The volume fraction of the $\mathrm{Cu}: \mathrm{Mg}$ co-clusters transformed is evaluated by:

$f^{\mathrm{cl}}=\frac{\left(\bar{c}-c_{\mathrm{e}}^{\mathrm{cl}}\right)}{c_{\beta}^{\mathrm{cl}}}$

where $c_{\beta}^{\mathrm{cl}}$ is the solute concentration in the $\mathrm{Cu}: \mathrm{Mg}$ co-clusters and $c_{\mathrm{e}}^{\mathrm{cl}}$ is the semi-equilibrium solvus of co-clusters which is described by a regular solution model (or solution product equation), i.e. [8]:

$\left[c_{\mathrm{e}}^{\mathrm{Cu}}\right]\left[c_{\mathrm{e}}^{\mathrm{Mg}}\right]=k_{1} \exp \left(\frac{-\Delta H_{\mathrm{cl}}}{R T}\right)$

where $k_{1}$ is a constant and $\Delta H_{\mathrm{cl}}$ is the formation enthalpy taken as $38 \mathrm{~kJ} / \mathrm{mol}$ (see [8], a similar value is identified in [43]). The 2024 aluminium alloy is assumed to be pseudo-binary with the concentrations of copper and magnesium in the Al-rich phase remaining equal during the entire ageing process. (Both for the $\mathrm{S}$ phase precipitates and the $\mathrm{Cu}-\mathrm{Mg}$ co-clusters, the $\mathrm{Cu}: \mathrm{Mg}$ ratio is $\sim 1)$. Thus the semi-equilibrium solvus of the solute in the co-clusters is:

$c_{\mathrm{e}}^{\mathrm{cl}}=k_{2}\left(\exp \left(\frac{-\Delta H_{\mathrm{cl}}}{R T}\right)\right)^{0.5}$

where $k_{2}$ is a constant which is derived by considering that the stability limit of the co-clusters in $2024 \mathrm{Al}-\mathrm{Cu}-\mathrm{Mg}$ alloy is $250^{\circ} \mathrm{C}$.

Nucleation of S phase: In the KW type model the evaluation of the nucleation rate of the precipitates is based on the classical nucleation theory [34], which is valid for the binary alloys and generally not considered strictly applicable for multi-component alloys [35]. In the model this is overcome by assuming the alloy is pseudo-binary (nucleation and growth of the precipitates is controlled by the diffusion of copper). The nucleation rate $(J)$ of the precipitates is calculated in the model by applying the approximation for homogeneous nucleation as used in a range of previous papers [9,34]: 
$J=N_{\mathrm{v}} \frac{k_{\mathrm{b}} T}{h} \exp \left(-\frac{4}{3} \frac{\pi \gamma_{\mathrm{n}} r^{* 2}}{R T}-\frac{E_{\mathrm{a}}}{R T}\right)$

where $\gamma_{\mathrm{n}}$ is the interfacial energy, $E_{\mathrm{a}}$ is the activation energy barrier for diffusion, $k_{\mathrm{b}}$ is the Boltzmann constant and $h$ is the Planck constant. $N_{\mathrm{v}}$ is the number of the nucleation sites per unit volume estimated as the number of solute atoms per unit volume [10,36] and $r^{*}$ is the critical size which is evaluated by the Gibbs-Thompson relationship [6]. The formulation of the Gibbs- Thompson often used is given by [10,33,35]:

$c_{\mathrm{i}}=c_{\mathrm{e}} \exp \left(\frac{2 \gamma V_{\mathrm{m}}}{r R T}\right)$

where $c_{\mathrm{i}}$ is the solute concentration at the precipitate/matrix interface, $V_{\mathrm{m}}$ is the molar volume of the precipitates and $c_{\mathrm{e}}$ is the equilibrium solute concentration that is calculated using the regular solution model [7,8] (with formation enthalpy $\Delta H_{\mathrm{S}}$ taken as $75 \mathrm{~kJ} / \mathrm{mol}[8]$ ).

However, in a recent study [37] it has been shown that the latter formulation is an approximation which is only applicably to precipitates for which the solute concentration in the matrix $\left(c_{\beta}\right)$ is equal to 1 . For intermetallic precipitates the correct approximation was shown to be [37]:

$c_{\mathrm{i}}=c_{\mathrm{e}} \exp \left(\frac{2 \gamma V_{\mathrm{m}}}{c_{\beta} r R T}\right)$

In the present model the critical radius is evaluated by the modified Gibbs-Thomson equation as:

$r^{*}=\frac{2 \gamma_{\mathrm{n}} V_{\mathrm{m}}}{c_{\beta} R T}\left[\ln \left(\frac{\bar{c}}{c_{\mathrm{e}}}\right)\right]^{-1}$

The equations (4) and (7) represent an approximation (ignoring the Zeldovitch factor [38]) that has been applied in previous works $[2,5,9,10]$ with some success, but it can be refined further to take into account more detailed theories of the atomic attachment rate and the Zeldovich factor $[3,4,35]$. In the $\mathrm{KW}$ model the nucleated precipitates can only grow if their size is greater than the critical size $[3,19$,$] . Generally the size of the nucleated precipitates is set 10 \%$ greater than the calculated critical size [10].

Growth/Coarsening of $\boldsymbol{S}$ phase: In the model the growth and coarsening of the existing groups of precipitates during each time step is evaluated by [39,40,41]:

$\mathrm{d} r=\frac{D}{r} \frac{\bar{c}-c_{\mathrm{i}}}{c_{\beta}-c_{\mathrm{i}}} \mathrm{d} t$ 
where $c_{\beta}$ is the solute concentration in the precipitate, $D$ is the diffusion coefficient, $r$ is the precipitate radius and $c_{\mathrm{i}}$ is the solute concentration at the precipitate/matrix interface that is evaluated by the modified Gibbs-Thompson relationship (Eq. 6) [6].

Coarsening arises naturally in the model when the average solute concentration in the matrix $(\bar{c})$ becomes larger than the solute concentration at the precipitate/matrix interface $\left(c_{\mathrm{i}}\right)$, thus resulting in the dissolution of the smaller precipitates $[6,10]$.

The main predictions of the microstructural model are the volume fraction of the $\mathrm{Cu}: \mathrm{Mg}$ coclusters and the average size and volume fraction of the $\mathrm{S}$ phase precipitates. The volume of the rod-like $S$ phase precipitates is evaluated by including the aspect ratio $\left(a_{\mathrm{r}}=l / 2 r\right)$, where $l$ is the length and $r$ is the cross-sectional radius of the precipitates. The value of $a_{\mathrm{r}}$ is taken as constant in the present model. The volume of each of the $\mathrm{S}$ phase precipitates $\left(V_{\mathrm{S}, j}\right)$ is evaluated by:

$V_{\mathrm{S}, j}=\pi r_{j}^{2} l_{j}=2 \pi r_{j}^{3} a_{\mathrm{r}}$

Strength Model: The critical resolved shear stress of the grains is determined by including the contributions due to the non-shearable $\mathrm{Cu}: \mathrm{Mg}$ co-clusters and the shearable $\mathrm{S}$ phase precipitates, the solute in the matrix and the dislocations introduced by cold-working.

Co-cluster Strengthening: The strengthening by the shearable co-clusters may, in principle, be due to mechanisms such as order strengthening, stacking fault strengthening, chemical strengthening or modulus strengthening [20,42]. In $2024 \mathrm{Al}-\mathrm{Cu}-\mathrm{Mg}$ alloys the co-cluster strengthening can be described well by modulus strengthening mechanism $[29,43]$. The increase in the critical resolved shear stress (CRSS) of the grains due to the co-clusters is determined by $[44,45,46$,$] :$

$\Delta \tau_{\mathrm{cl}}=\frac{\Delta \mu}{4 \pi \sqrt{2}} \sqrt{f_{\mathrm{cl}}}$

where $f_{\mathrm{cl}}$ is the volume fraction of the co-clusters and $\Delta \mu$ is the difference in the shear modulus of the matrix and the co-clusters, which is adjusted to fit the predicted strength to the experimental results and has a value equal to $0.372 \mathrm{GPa}$. This procedure was justified elsewhere [43].

$S$ phase Strengthening: S phase precipitates are approximately rod shaped and aligned in the $\{100\}$ directions. They are considered non-shearable, and hence strengthening is based on the Orowan looping mechanism [8]. Through computer simulation of equilibrium configurations of a dislocation interacting with randomly distributed non-shearable circular obstacles of finite size in a slip plane, Zhu and Starke [47] identified the following modification of the Orowan equation: 
$\Delta \tau_{\mathrm{S}}=\frac{0.82 \mu_{\mathrm{Al}} b}{2 \pi L_{\mathrm{cc}}} \ln \left(\frac{D}{r_{\mathrm{o}}}\right)\left(1+0.83 \frac{D}{L_{\mathrm{cc}}}+1.91\left(\frac{D}{L_{\mathrm{cc}}}\right)^{2}\right)$.

where $D$ is the diameter of the obstacle, $L_{\mathrm{cc}}$ is the planar (centre to centre) spacing between the obstacles in the slip plane, $b$ is the Burgers vector and $r_{\mathrm{o}}$ is the inner cut-off radius for calculation of the dislocation line tension, which is generally considered equal to the Burgers vector.

In the case of rod-like precipitates oriented along $\{100\}$ for which length of the precipitates $\left(L_{\mathrm{r}}\right)$ is much larger than the diameter $\left(D_{\mathrm{r}}\right)$, it holds [47]:

$$
\begin{aligned}
& D=\frac{D_{\mathrm{r}}}{\sqrt{\cos \left(54.7^{\circ}\right)}} . \\
& L_{\mathrm{cc}}=D_{\mathrm{r}} \sqrt{\frac{\pi}{4 f \cos \left(54.7^{\circ}\right)}} .
\end{aligned}
$$

where $f$ is the volume fraction of the rod-shaped precipitates.

Using the latter two expressions for $D$ and $L_{\mathrm{cc}}$, Eq. 10 may be written as:

$$
\Delta \tau_{\mathrm{S}}=\frac{0.112 \mu_{\mathrm{Al}} b}{D_{\mathrm{r}}} \ln \left(\frac{1.316 D_{\mathrm{r}}}{r_{\mathrm{o}}}\right)\left(f^{1 / 2}+0.94 f+2.44 f^{3 / 2}\right) .
$$

(Note that whilst the derivation is similar, the latter equation is different to the one in Ref [47].)

Whilst Eq. 13 is considered to be the most advanced treatment of strengthening due to nonshearable rod shaped precipitates it was noted that good results in modelling could only be achieved by introducing a factor equal to 1.4 in the equation. It is indeed common practice to use one adjustable factor for the strengthening contribution due to precipitates in models similar to this one. Thus we added the factor 1.4 to Eq. 13; and we will discuss this issue in Section 4.

Total CRSS of the grains: The total CRSS of the grains $\left(\Delta \tau_{\text {tot }}\right)$ is evaluated by using the phenomenological Pythagorean and linear superposition approximations, which are used for summation of the obstacle strengths of similar and different magnitudes, respectively $[48,49]$ :

$$
\Delta \tau_{\mathrm{tot}}=\Delta \tau_{\mathrm{ss}}+\sqrt{\Delta \tau_{\mathrm{S}}^{2}+\Delta \tau_{\mathrm{cl}}^{2}+\Delta \tau_{\mathrm{d}}^{2}}
$$

where $\Delta \tau_{\mathrm{ss}}$ and $\Delta \tau_{\mathrm{d}}$ are the increase in CRSS of the grains due to the solute in the matrix $[1,50]$ and the dislocations [46], respectively and determined by:

$$
\Delta \tau_{\mathrm{ss}}=k_{\mathrm{ss}}(\bar{c})^{\mathrm{m}}
$$


$\Delta \tau_{\mathrm{d}}=\frac{k_{\mathrm{a}}}{M} \sqrt{\varepsilon}$

where $k_{\mathrm{ss}}$ is a constant calculated on the basis of data on strength of binary (Al-Mg and Al-Cu) dilute solid solutions [51], $\bar{c}$ is the concentration of the solute, $\mathrm{m}$ is a constant that has been taken in the past as either $2 / 3[1,50]$ or 1 [52]. Due to the very small levels of dissolved elements, the choice of $\mathrm{m}$ does not significantly influence model predictions, and in the present model it is taken as $1 . \varepsilon$ is the plastic strain and $k_{\mathrm{a}}$ is the strain hardening factor, which depends on microstructural parameters. $M$ is a factor (also referred to as the Taylor factor) that depends on the texture and the orientation of the tensile axis relative to the main axes of the worked specimen [7]. Following the results of self consistent models, $M$ is taken as 2.6, which is valid for texture free equi-axed grains in face centred cubic (FCC) metals [53].

In order to compare with the measured hardness values the total CRSS of the grains is converted to yield strength by applying the factor $M$ and estimated values of grain boundary strengthening [53].

The input parameters used in the model are summarized in Table 1, and they will be discussed below.

\section{Experimental}

The model predictions are verified by the yield strength and calorimetry data measured on a 2024-T351 aluminium alloy. The 2024-T351 Al-Cu-Mg alloy used in the experiments was supplied in the form of $12.5 \mathrm{~mm}$ thick plate. The alloy composition is $4.2 \mathrm{wt} . \% \mathrm{Cu}$, 1.36 wt. $\%$ Mg, 0.58 wt.\% Mn, 0.06 wt.\% Si and 0.08 wt.\% Fe with balance Al. The material was solution treated, stretched (2\%) and aged at room temperature for several months to obtain a stable state.

Tensile testing: Isothermally aged samples were tensile tested on an Instron 1196 tensile testing machine with a crosshead speed of $10 \mathrm{~mm} / \mathrm{min}$ at room temperature in accordance with ASTM standard E8. A strain gauge extensometer with a gauge length of $12.5 \mathrm{~mm}$ and a travel distance of $5 \mathrm{~mm}$ was employed to measure the strain. Samples $(\sim 20 \mathrm{~mm}$ long, $12 \mathrm{~mm}$ wide and $12 \mathrm{~mm}$ thick) were aged in an air-circulating electric furnace at $170,190,200$ and $220^{\circ} \mathrm{C}$ for different ageing times. Two samples for each heat treatment condition were tensile tested.

DIC experiments : DIC experiments were performed using a Perkin Elmer Pyris-1 power compensation type instrument. Samples $(\sim 5 \mathrm{~mm} \mathrm{x} \sim 5 \mathrm{~mm} \mathrm{x} \sim 2 \mathrm{~mm})$ were cut using a precision saw, the corners were ground and the surfaces were polished up to 1200 grit. The results were obtained by isothermal ageing of the samples at 200 and $220^{\circ} \mathrm{C}$.

Transmission Electron Microscopy (TEM): 2024-T351 samples aged at $190^{\circ} \mathrm{C}$ for $96 \mathrm{~h}(4$ days) and 720h (30 days) were investigated in a Jeol JEM 3010 transmission electron microscope. The TEM samples were prepared by cutting a thin slice $(\sim 0.3 \mathrm{~mm})$, grinding it to 
a thickness of about $0.15 \mathrm{~mm}$ and punching $3 \mathrm{~mm}$ diameter discs. The samples were polished in a twin jet electro-polisher using a $30 \% \mathrm{HNO}_{3}$ solution in methanol maintained between -20 and $-30^{\circ} \mathrm{C}$. Digital bright field (BF) images and corresponding selected area electron diffraction (SAD) patterns were taken near the [001] zone axis.

Quantitative microstructural measurements were performed on BF TEM images using Carl Zeiss KS300 image analysis software. Several BF images from different locations were analyzed for each ageing condition. For images with good contrast between the precipitates and the matrix, a semi-automated procedure for identifying the edge-on variants of the $\mathrm{S}$ phase precipitates was adopted. Incomplete precipitates at the edge of the image were excluded from the analysis. Images with relatively poor contrast were measured manually by selecting the precipitates of interest on the background corrected images using an interactive measurement method. The resulting binary images contained some artefacts introduced by contrast due to precipitates normal to the edge on variants and by overlapping of precipitates. This was corrected by excluding objects with filled area larger than 2000 pixel $^{2}$ or smaller than 60 pixel $^{2}$ or with a maximum to minimum feret ratio larger than 5 .

\section{Results and Discussion}

Model Parameters: Most of the parameters for the model including the aspect ratio of the $\mathrm{S}$ phase rods can be determined from literature data. For instance, the aspect ratio is approximately constant and equals on average about 10 . Other parameters obtained from literature are given in Table 1.

However, an important parameter in the model, the interfacial energy for the $\mathrm{S}$ phase precipitates is difficult to measure experimentally and no values are available in the literature. The interfacial energy is therefore obtained by fitting the model predictions to the experimental results, which has been employed in many similar models based on the KW model [4]. The main challenge in developing the model proved to be the prediction of the strength for different ageing temperatures using a constant interfacial energy. If the value of the interfacial energy is independent of temperature, the predicted strength values increase significantly with the decrease in temperature due to an increase in the maximum number of precipitates. This is not in agreement with the strength data measured in these alloys after isothermal ageing, which shows very small changes in the peak strength as a function of the ageing temperature. In fact, most age hardening Al based alloys show relatively small changes in peak strength with ageing temperature. Thus, the only way in which a model with the present or similar temperature dependence of nucleation rate can describe the observed strength data is by including a temperature dependent interfacial energy. Indeed, in some recent works the dependence of the interfacial energy on the precipitate size during ageing has been discussed $[10,54]$. We attempted temperature dependent correction terms with $T$ (linear), $1 / T, T^{2}$ and $T^{3}$ dependency. All yielded almost similar strength values for temperatures between 170 and $220^{\circ} \mathrm{C}$ but, especially the linear and the $1 / T$ terms caused deviations for temperatures lower than $170^{\circ} \mathrm{C}$ and higher than $220^{\circ} \mathrm{C}$. The $T^{3}$ term provided the best results and hence the interfacial energy within the nucleation regime (when the nucleation rate $>0$ ) is taken as: 
$\gamma_{\mathrm{n}}=\gamma_{\mathrm{n}, 0}-\mathrm{a} T^{3}$

where $\gamma_{\mathrm{n}}$ is the interfacial energy for nucleation (units $\mathrm{J} / \mathrm{m}^{2}$ ), $T$ is the absolute temperature, and $\gamma_{\mathrm{n}, 0}$ and a are fitting parameters with values $0.076 \mathrm{~J} / \mathrm{m}^{2}$ and $1.2 \times 10^{-10} \mathrm{~J} / \mathrm{m}^{2} \mathrm{~K}^{3}$, respectively. The interfacial energy for growth is equal to the interfacial energy for nucleation within the nucleation regime. In the coarsening regime (when the nucleation rate equals 0 ), however, the interfacial energy for nucleation is not sufficient to cause the timely coarsening of the precipitates and therefore an unrealistically long steady state occurs in between the nucleation/growth and the coarsening growth regimes. It has been previously discussed that the prediction of the nucleation and growth using a single interfacial energy value is generally unsuccessful because the interfacial energy measured for coarsening is too large to give a reasonable nucleation rate, and the interfacial energy for nucleation is too small to give the correct coarsening behaviour [10]. In the present model the interfacial energy during the coarsening regime is taken as:

$\gamma_{\mathrm{g}}=\gamma_{\mathrm{n}}+\Delta \gamma$

where $\Delta \gamma$ is a fitting constant which is found to be equal to $0.325 \mathrm{~J} / \mathrm{m}^{2}$.

Table 1 : Summary of input data used in the model

\begin{tabular}{|l|l|c|}
\hline Parameter & \multicolumn{1}{|c|}{ Value } & Source / Notes \\
\hline$\Delta H^{c l}$ & $38 \mathrm{~kJ} / \mathrm{mol}$ & {$[8]$} \\
\hline$\Delta H^{S}$ & $75 \mathrm{~kJ} / \mathrm{mol}$ & {$[8]$} \\
\hline$E_{a}$ & $135 \mathrm{~kJ} / \mathrm{mol}$ & Based on estimates in [43] \\
\hline$c_{\beta}^{c l}$ & 10 at. $\%$ & \\
\hline$c_{\beta}^{S}$ & 25 at. $\%$ & {$[51]$} \\
\hline$V_{m}$ & $10^{-5} \mathrm{~m}^{3} / \mathrm{mol}$ & [43] \\
\hline$a_{r}$ & 10 & Measured from TEM micrographs in [51] \\
\hline$k_{s s}$ & $24.5 \mathrm{MPa} / \mathrm{at} . \%$ & \\
\hline$\Delta \mu$ & $0.372 \mathrm{GPa}$ & \\
\hline$b$ & $0.2864 \mathrm{~nm}$ & \\
\hline
\end{tabular}

Comparison with experimental data: In Fig.1(a) the model predictions for the changes in yield strength during isothermal treatments is compared with the experimentally measured yield strength after isothermal ageing at four different temperatures $\left(220,200,190\right.$ and $\left.170^{\circ} \mathrm{C}\right)$. There is a good agreement between the model predictions and the experimental results. The predictions of the microstructural model for the evolution of the $\mathrm{S}$ phase precipitates are tested 
by comparing the predicted heat flow during the nucleation and growth of the $\mathrm{S}$ phase precipitates during isothermal treatments with the heat flow measured during isothermal ageing at 220 and $200^{\circ} \mathrm{C}$ in the calorimeter as presented in Fig. 1(b). The predicted and measured heat flows for $\mathrm{S}$ phase formation are also in good agreement. (The modelled heat flow should be proportional to $\mathrm{d} V_{\mathrm{S}} / \mathrm{d} t$ and the regular solution model predicts it should be equal to $\mathrm{d} H_{\mathrm{S}} \times \mathrm{d} V_{\mathrm{S}} / \mathrm{d} t$. Indeed, peak heat flows correspond closely to this prediction. We have added normalizing factors, all close to unity, such that peak heat flows coincide.)

Fig. 1 (a) Predicted strength (curves) compared with measured strength (symbols) and (b) predicted heat flow (curves) compared with DIC results (symbols) during isothermal ageing at different temperatures.

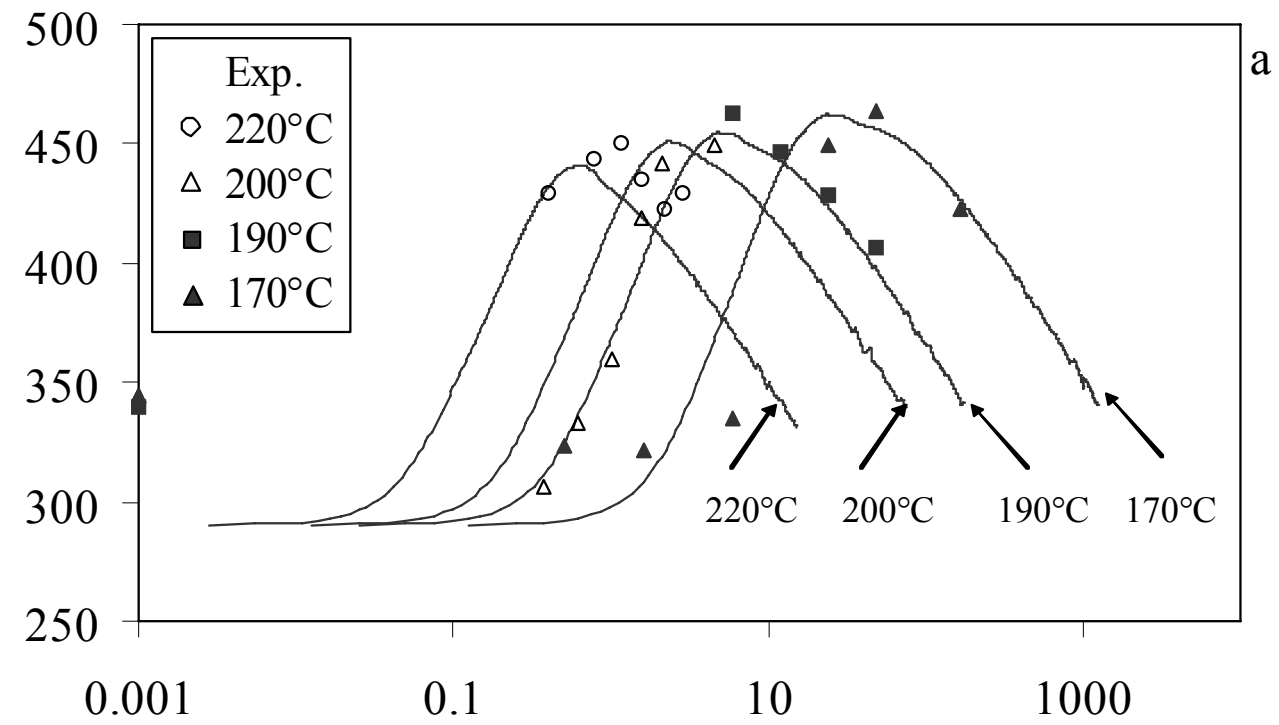

Log Time (h)

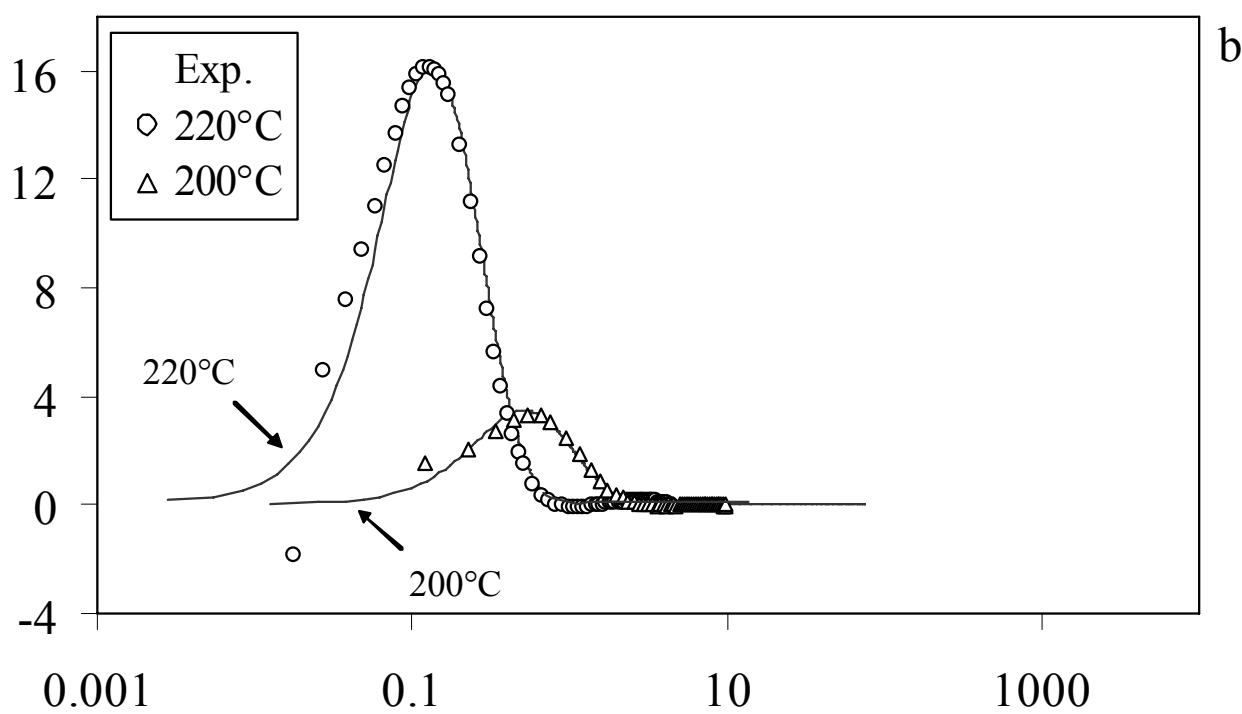

Log Time (h) 
The predicted size of the S phase formed during isothermal treatments has also been tested by experimentally measuring the precipitate size by image analysis of the TEM micrographs of 2024-T351 samples aged for 96 and $720 \mathrm{~h}$ at $190^{\circ} \mathrm{C}$, which are presented in Fig. 2 and 3, respectively. The SAD patterns are fully consistent with the twelve $\mathrm{S}$ phase variants with the main axis aligned along the three $\{100\}$ directions [24]. No extra reflections by other precipitates were resolved. Image analysis has been performed on the end-on $\mathrm{S}$ phase precipitates to characterize the distribution of equivalent diameters, and the results are presented in Table 2. The comparison of the predicted size of the $\mathrm{S}$ phase precipitates after isothermal ageing at $190^{\circ} \mathrm{C}$ for 96 and $720 \mathrm{~h}$ with the sizes measured from TEM analysis are presented in Fig. 4. It is observed that the predicted sizes of the S phase precipitates correspond very well with the measured sizes: deviations are within about $4 \%$ and are almost equal to the standard errors of the average size measurements.

Table 2 The measured mean equivalent diameters of end-on $\mathrm{S}$ precipitates as obtained from TEM

\begin{tabular}{|c|c|c|c|c|}
\hline $\begin{array}{c}\text { Ageing treatment } \\
\left(\mathrm{h} /{ }^{\circ} \mathrm{C}\right)\end{array}$ & $\begin{array}{c}\text { Mean diameter } \\
(\mathrm{nm})\end{array}$ & $\begin{array}{c}\text { Std. deviation } \\
(\mathrm{nm})\end{array}$ & $\begin{array}{c}\text { Std. error* } \\
(\mathrm{nm})\end{array}$ & $\begin{array}{c}\text { Measured } \\
\text { Precipitates (No.) }\end{array}$ \\
\hline $96 / 190$ & 14.3 & 5.8 & 0.3 & 487 \\
\hline $720 / 190$ & 25.0 & 4.9 & 0.9 & 32 \\
\hline
\end{tabular}

*Standard error $=$ standard deviation in the sample $/(\text { number of measured precipitates })^{0.5}$

The model: achievements and limitations: Modelling of microstructural changes using the KW model has been applied in a range of papers [9-10,35,37], and in some works strength predictions have also been made [2-6]. However in these previous works the assessment of the model was usually limited to comparison with only strength data and/or precipitate size data. The present work represents the first attempt at the construction of a two-stage (and two precipitate) ageing model based on the KW numerical model, which is tested against measurements of both the heat flow and strength during isothermal treatments. The model accuracy is very good considering the wide range of data against which it is tested.

A further assessment of model reliability can be made by comparing the fitted parameters with data on these parameters. This comparison is generally favourable. For instance, the interfacial energy during the coarsening regime $\left(\sim 0.5 \mathrm{~J} / \mathrm{m}^{2}\right)$ is lower than the interfacial energies reported for incoherent precipitates, which are generally in the order of $1 \mathrm{~J} / \mathrm{m}^{2}[55]$; but they are somewhat higher than interfacial energies reported for fully coherent particles, which are generally in the order of $0.2 \mathrm{~J} / \mathrm{m}^{2}$ (see e.g. work on $\mathrm{Al}_{3} \mathrm{Zr}$ precipitates in $\mathrm{Al}$ [11] and on $\eta$ precipitates in $\mathrm{Al}$ [35]). However, in the case of the interfacial energy it should be noted that in the present model a treatment derived for spherical particles is applied to precipitates that are rod or lath shaped, in which interfacial energies will be different for the different faces. Thus comparisons between fitted (average) interfacial energy adopted in the present model and 
assessments of interfacial energy by other means or in other alloys, should be considered with caution. The interfacial energy during nucleation determines to a large extent the size of the $\mathrm{S}$ phase precipitates at the stage where the maximum volume fraction is reached.

Fig. 2 TEM micrograph (a) (bright field, B= [001]) and corresponding SAD (b) for the 2024$\mathrm{T} 351$ alloy aged for $96 \mathrm{~h}$ at $190^{\circ} \mathrm{C}$.

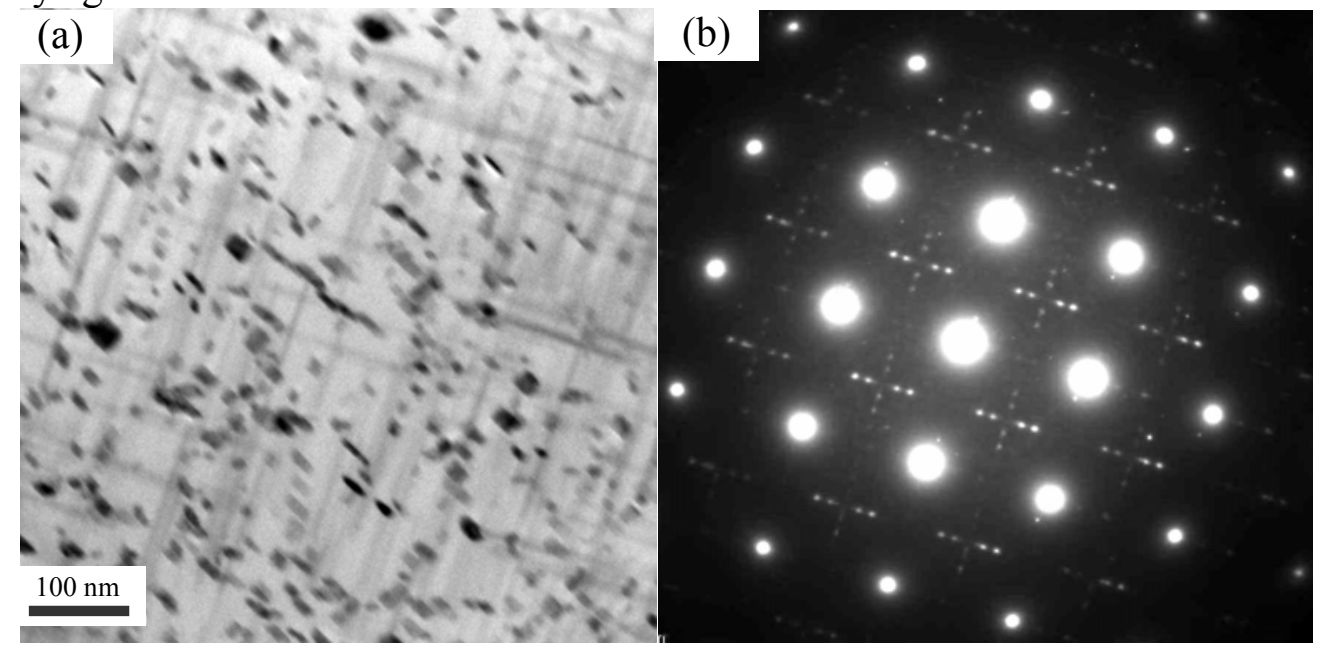

An important issue in interpreting the KW model is the need for the interfacial energy to increase during the transformation [10,54]; in the present work this is treated by using different interfacial energies for the nucleation stage and for the coarsening stage. In research on Al-Zn$\mathrm{Mg}-\mathrm{Cu}$ alloys it has been suggested that this may be related to the size of the $\eta$ precipitate, with the interfacial energy being a monotonically increasing function of the precipitate size [54]. Such an approach may also be suitable for our present alloy, and further research would be needed. Other researchers [35] have suggested that in the Al- $\mathrm{Zn}-\mathrm{Mg}-\mathrm{Cu}$ system a transformation from a well-defined precursor phase, $\eta$ ', to $\eta$, with the interfacial energy of the precursor much lower than that of $\eta$, can provide an accurate model. This approach appears unsuited for the $\mathrm{S}$ phase formation, as recent work indicates that $\mathrm{S}$ phase does not have a precursor phase that is consumed during $S$ phase formation $[29,56]$. (In particular, the $S^{\prime}$ precipitates are essentially $S$ phase with a slightly different orientation ratio [56] and $S^{\prime \prime}$ phase does not appear to transform into $\mathrm{S}$ phase [30]. It is also noted that neither of the two approaches discussed will in itself reduce the number of parameters to be fitted.)

In the model we used an additional factor for strengthening due to rod shaped precipitates of 1.4, which thus increased their strengthening contribution by $40 \%$ as compared to Eq 13 which is derived on the basis of purely geometrical considerations for perfectly cylindrical particles. The limited increase applied can be justified from two considerations. Firstly, precipitates are not quite perfect cylinders, and deviations from perfect cylinders will increase the strengthening contribution. Secondly, hampering of dislocation movement due to the strain field in the matrix near the precipitates is likely to occur, which would increase strengthening proportional to the volume fraction of $\mathrm{S}$ phase. 
Fig. 3 TEM micrograph (a) (bright field, $B=[001]$ ) and corresponding SAD (b) for the 2024T351 alloy aged for $720 \mathrm{~h}$ at $190^{\circ} \mathrm{C}$.

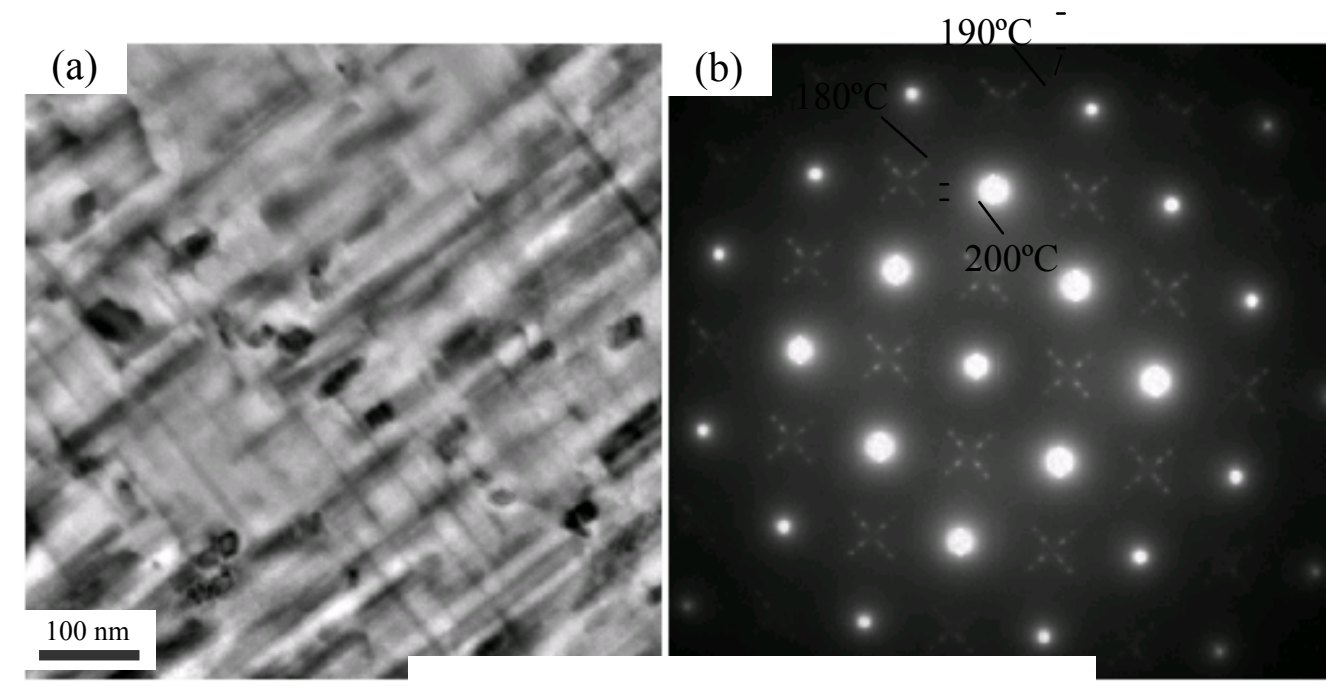

Fig. 4 Measured radius (symbols) of S phase rods after ageing at $190^{\circ} \mathrm{C}$ compared with model predictions (curves). Error bars indicate standard deviation of the sample and standard error of the measured mean.

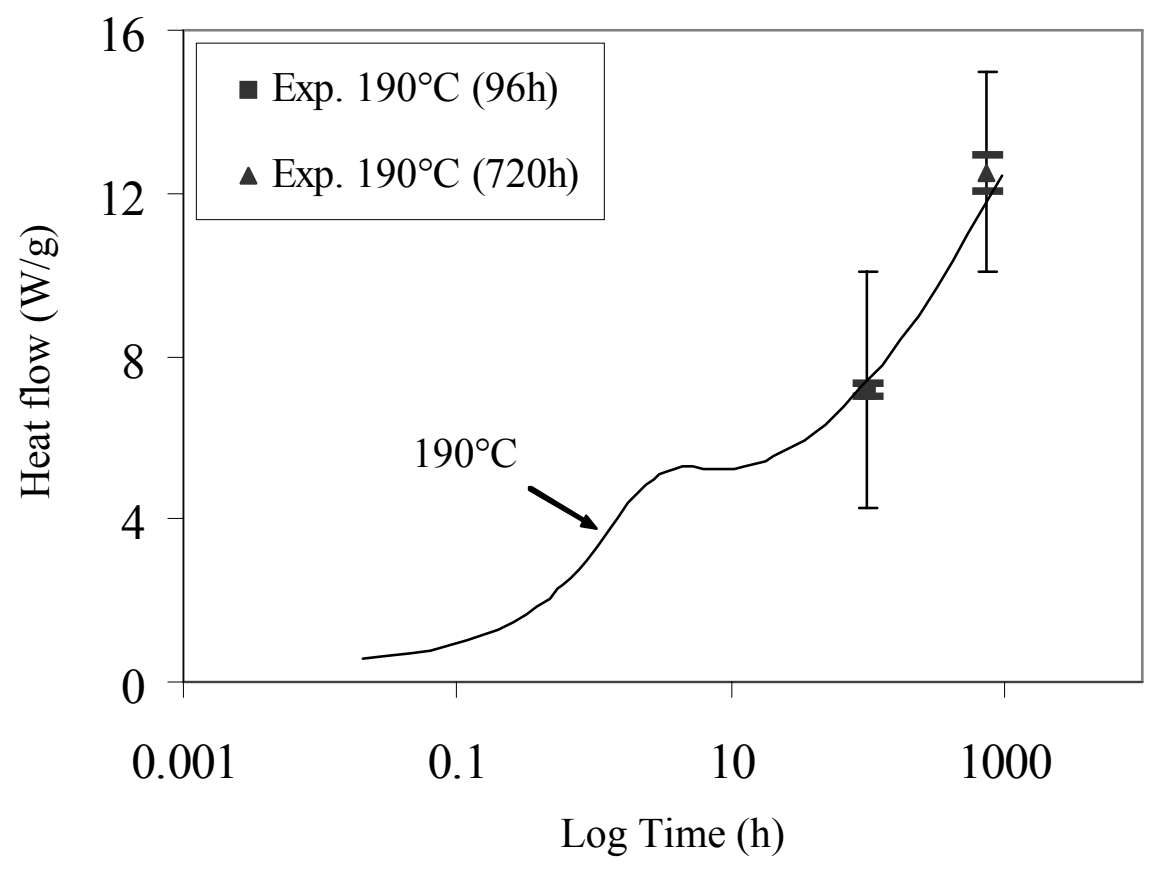


Fig. 5 (a) DSC curves for $2024 \mathrm{~T} 351$ alloy for 3 different heating rates $\left(5^{\circ} \mathrm{C} / \mathrm{min}, 10^{\circ} \mathrm{C} / \mathrm{min}\right.$ and $20^{\circ} \mathrm{C} / \mathrm{min}$ ) (b) Plot of $\ln \left(T_{p}^{2} / \beta\right)$ as a function of $1 / T$, where $T_{P}$ is the peak temperature and $\beta$ is the heating rate and $E_{a}$ is the slope of the curve.
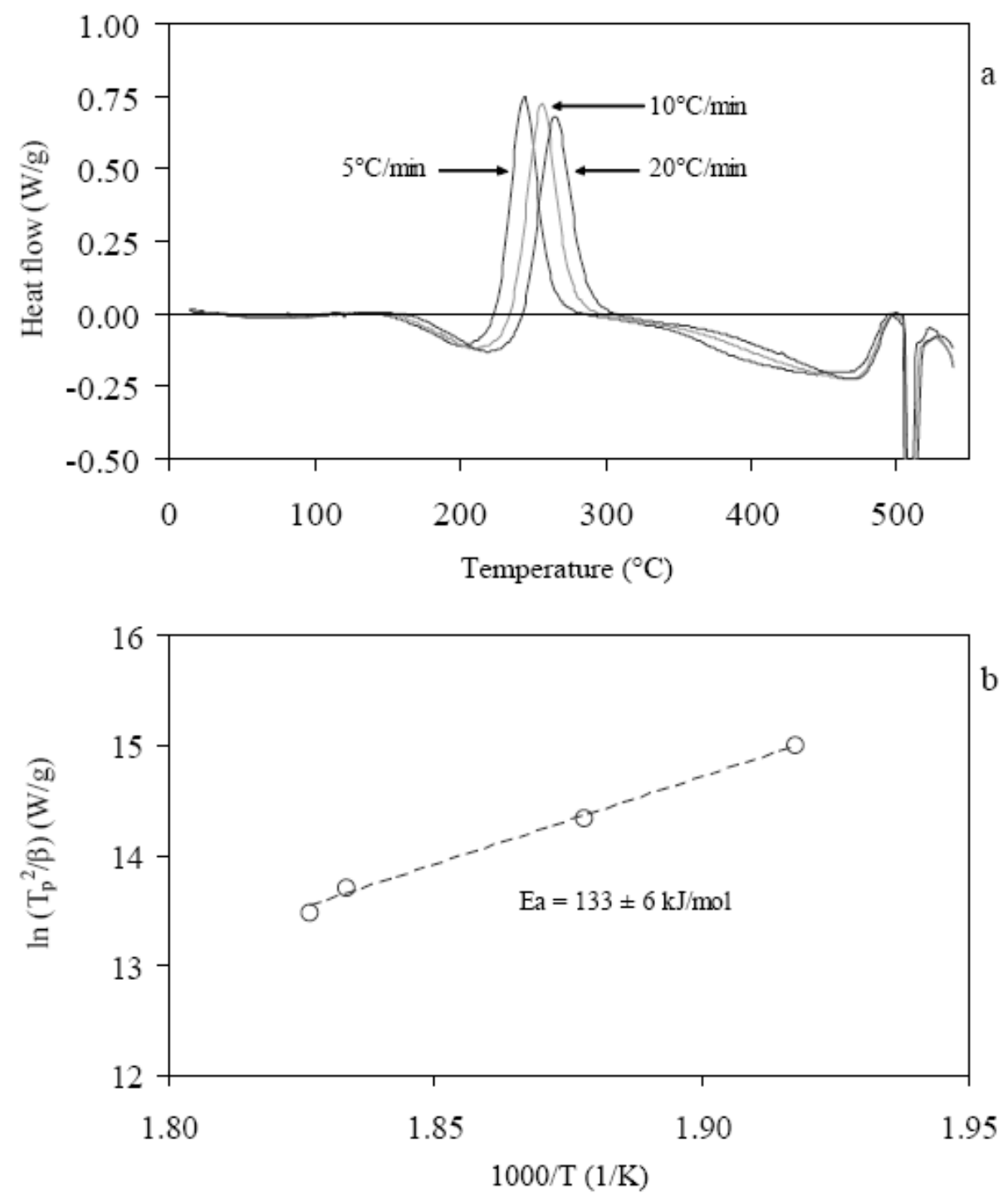

An important parameter in the model is the activation energy for the diffusion $\left(E_{\mathrm{a}}\right)$ in Eq. 4. This activation energy should be equal to the activation energy for $\mathrm{S}$ phase formation, which can be derived from experiments which measure the rate of $\mathrm{S}$ formation at different temperatures. For the present analysis, the activation energy is obtained from DSC experiments performed on a 2024-T351 alloy at different heating rates using iso-conversion methods [57,58]. Fig. 5 presents the DSC curves for heating rates of $4.63,4.72$ and $4.9 \mathrm{~K} / \mathrm{s}$ (or 5,10 and $20^{\circ} \mathrm{C} / \mathrm{min}$, respectively). The dominant exothermic heat effect situated between about 220 and $280^{\circ} \mathrm{C}$ is due to $\mathrm{S}$ phase formation; this and other heat effects have been discussed elsewhere $[24,29,43,59]$. The activation energy is calculated by evaluating the slope of the plot of $\ln \left(T_{\mathrm{p}}^{2} / \beta\right)$ versus $1 / T$ [57] in Fig.5(b), where $T_{\mathrm{p}}$ is the peak temperature and $\beta$ is the heating rate. (In Fig. 5 (b) an additional data point for heating rate $\sim 5 \mathrm{~K} / \mathrm{s}\left(25^{\circ} \mathrm{C} / \mathrm{min}\right.$ ) is also included). The measured activation energy $(133 \pm 6 \mathrm{~kJ} / \mathrm{mol})$ is fully consistent with the 
activation energy for diffusion adopted in the model $(135 \mathrm{~kJ} / \mathrm{mol})$ which provides a further indication that the transformation kinetics part of the model is sound.

The comparisons with experimental data show that applying the KW approach, which was originally derived for spherical particles, to the present elongated precipitates, provides a good correspondence. Thus it appears that the KW model is a good approximation for these elongated particles. One of the reasons for this good correspondence is that elongated particles in many cases will grow in all 3 orthogonal directions, whilst maintaining (in good approximation) their basic shape, i.e. by maintaining their aspect ratio $[12,60]$. Then the growth rate in the 3 orthogonal directions at the stage before significant impingement occurs is proportional to $t^{0.5}$ and the volume will grow as $t^{1.5}$, which is consistent with the KW model. Soft impingement (i.e. impingement of diffusion fields) related to growth of elongated particles will be different from that for equi-axed particles, and there is reason to suspect that the KW model can not be a physically accurate model for this stage. However, possible deviations introduced by inaccurate descriptions of impingement occur in a stage where the interfacial energy in the model changes from the nucleation stage interfacial energy to the growth stage interfacial energy. The way this change occurs has been treated different by different researchers (either gradually, as in [54], or in a step change, as employed in the present work), without there being a generally accepted treatment, and more detailed studies would be needed to resolve potential sources of inaccuracies in this stage. Notwithstanding these reservations, the excellent correspondence between measured and predicted rate of transformation in Fig. $2 \mathrm{~b}$ serves to show that the even though there is no theoretical proof of the KW model for the case of elongated particles, it is very accurate.

The next stage in the present research involves applying the model to heat treatments applied in industry. In subsequent work we will demonstrate how it can be used to non isothermal treatments and to predict local microstructure and strength in welds [61].

\section{Conclusions}

A numerical model based on the KW model has been developed for the prediction of the changes in the strength in Al-Cu-Mg alloys during isothermal treatments. The model includes strengthening contributions due to shearable $\mathrm{Cu}: \mathrm{Mg}$ co-clusters, the non-shearable $\mathrm{S}$ phase precipitates, the solute in the matrix and the dislocations. The predictions are tested by comparing with the strength data and with calorimetry data on 2024-T351 aluminium alloys. There is a good agreement between the model predictions and the experimental results. To obtain realistic predictions the interfacial energy needs to be temperature dependent, and needs to increase substantially in the coarsening stage.

\section{Acknowledgements}

The authors thank Dr Shuncai Wang for help with the TEM work. 


\section{References}

[1] H.R. Shercliff, M.F. Ashby, Acta Mater. 38 (1990) 1789

[2] D.H. Bratland, O. Grong, H.R. Shercliff, O.R. Myhr, S. Tjotta, Acta Mater. 45 (1997) 1

[3] A. Deschamps, Y. Brechet, Acta Mater. 47 (1999) 293

[4] J.C. Werenskiold, A. Deschamps, Y. Brechet, Mater. Sci. Eng. A 293 (2000) 267

[5] O.R. Myhr, O. Grong, S.J. Andersen, Acta Mater. 49 (2001) 65

[6] O.R. Myhr, O. Grong, H.G. Fjaer, C.D. Marioara, Acta Mater. 52 (2004) 4997

[7] M.J. Starink, S.C. Wang, Acta Mater. 51 (2003) 5131

[8] M.J. Starink, J.L. Yan, Mater. Sci. Forum 519-521 (2006) 251

[9] J.D. Robson, P.B. Prangnell, Acta Mater. 49 (2001) 599

[10] J.D. Robson, Acta Mater. 51 (2003) 1453

[11] J.D. Robson, Acta Mater. 52 (2004) 1409

[12] G. Liu, G.J. Zhang, X.D. Ding, J. Sun, K.H. Chen, Mater. Sci. Eng. A 344 (2003) 113

[13] S. Esmaeili, D.J. Lloyd, W.J. Poole, Acta Mater. 51 (2003) 2243

[14] W.A. Johnson, R.F. Mehl, Trans. Am. Inst. Miner. (Metall.) Eng. 135 (1939) 227

[15] M.J. Avrami, Phys. Chem. 7 (1939) 1103

[16] A.N. Kolmogorov, Bull. Acad. Sci. USSR, Phy. Ser. 3 (1937) 355

[17] I.M. Liftshitz, V.V. Slyozov, Chem. Solids 19 (1961) 35

[18] C. Wagner, Z. Elektrochem. 65 (1961) 581

[19] R. Wagner, R. Kampmann, in: R. Cahn, P. Haasen, E.J. Kramer (Eds.) Mater. Sci. Tech.: A Comprehensive Treatment: Phase Transformations in Mater.', Vol. 5.,. Wiley$\mathrm{VCH}, 1991$

[20] E. Nembach, Particle Strengthening of Metals and Alloys, John Wiley and Sons Inc, New York, USA, 1997

[21] N. Kamp, N. Gao, M.J. Starink, I. Sinclair, Int. J. Fatigue 29 (2007) 869

[22] S.P. Ringer, K. Hono, I.J. Polmear, T. Sakurai, Appl. Surf. Sci. 94-95 (1996) 253

[23] P. Ratchev, B. Verlinden, P. De Smet, P. Van Houtte. Acta Mater. 46 (1998) 3523

[24] S.C. Wang, M.J. Starink, Int. Mater. Rev. 50 (2005) 193

[25] P.I. Gouma, D.J. Lloyd, M.J. Mills, Mater. Sci. Eng. A 319-321 (2001) 439

[26] A.M. Zahra, C.Y. Zahra, Scr. Mater. 39 (1998) 1558

[27] Y.A. Bagaryatsky, Dokl. Akad. SSSR 87 (1952) 559

[28] S.C. Wang, M.J. Starink, Mater. Sci. Eng. A 386 (2004) 156

[29] S.C. Wang, M.J. Starink, N. Gao, Scr. Mater. 54 (2006) 287

[30] L. Kovarik, M.K. Miller, S.A. Court, M.J. Mills, Acta Mater. 54 (2006) 1731

[31] N. Gao, L. Davin, S. Wang, A. Cerezo, M.J. Starink, Mater. Sci. Forum 396-402 (2002) 923

[32] Y. Nagai, M. Murayama, Z. Tang, T. Nonaka, K. Hono, M. Hasegawa, Acta Mater. 49 (2001) 913

[33] M. Nicolas, A. Deschamps, Acta Mater. 51 (2003) 6077

[34] J.W. Christian, Theory of Transformations in Metals and Alloys, Part 1, Pergamon Press, Oxford, UK, 1975

[35] N. Kamp, A. Sullivan, R. Tomasi, J.D. Robson, Acta Mater. 54 (2006) 2003

[36] M.J. Stowell, Mater. Sci. Tech. 18 (2002) 139

[37] M. Perez, Scr. Mater. 52 (2005) 709

[38] K.C. Russell, Adv. Colloid Interfac. Sci. 13 (1980) 205

[39] C. Zener, J. Appl. Phy. 20 (1949) 950

[40] H.B. Aaron, D. Fainstain, G.R. Kotler, J. Appl. Phy. 41 (1970) 4404

[41] J.S. Langer, A.J. Schwartz, Phy. Rev. A 21 (1980) 948 
[42] D.N. Seidman, E.A. Marquis, D.C. Dunand, Acta Mater. 5 (2002) 4021

[43] M.J. Starink, N. Gao, L. Davin, J.L. Yan, A. Cerezo, Phil. Mag. 85 (2005) 1395

[44] L. Cartaud, J. Guillot, J. Grilhe, In: Proceedings of 4th International Conference on the Strength of Metals and Alloys, ICSMA 4, Nancy, France, Vol. 1, 1976, pp. 214

[45] P. Gomiero, Y. Brechet, F. Louchet, A. Tourabi, B. Wack, Acta Mater. 40 (1992) 857

[46] M.J. Starink, P. Wang, I. Sinclair, P.J. Gregson, Acta Mater. 47 (1999) 3855

[47] A.W. Zhu, E.A. Starke, Acta Mater. 47 (1999) 3263

[48] C. Genevois, A. Deschamps, A. Denquin, B. Doisneau-Cottignies, Acta Mater. 53 (2005) 2447

[49] E. Nembach, Acta Mater. 40 (1992) 3325

[50] U.F. Kocks, A.S. Argon, M.F. Ashby, Prog. Mater. Sci. 19 (1975) 1

[51] J.L. Yan, Ph.D. Thesis, Southampton, UK: Univ. of Southampton 2006

[52] J.R. Davis, ASM Speciality Handbook: Aluminium and Aluminium Alloys, Material Park, Ohio, ASM Int.,1993

[53] B. Clausen, T. Lorentzen, T. Leffers, Acta Mater. 46 (1998) 3087

[54] C. Sigli, Mater. Sci. Forum 519-521 (2006) 321

[55] M. van Rooyen, E.J. Mittemeijer, Metall. Trans. A 20 (1989) 1207

[56] S.C. Wang, M.J. Starink, Acta Mater, 55 (2007) 933

[57] M.J. Starink, Therm. Acta 404 (2003)163

[58] M.J. Starink, J. Mater. Sci. 42 (2007) 483

[59] M.J. Starink, A. Cerezo, J.L. Yan, N. Gao, Phil. Mag. Let. 86 (2006) 243

[60] M.J. Starink, Mater. Sci. Forum 539 (2007) 2365

[61] I.N. Khan, M.J. Starink, S.C. Wang, in preparation 